\title{
Genética da resistência à ferrugem-da-folha em aveia ${ }^{(1)}$
}

\begin{abstract}
Renata Pereira da Cruz ${ }^{(2)}$, Luiz Carlos Federizzi ${ }^{(3)}$ e Sandra Cristina Kothe Milach ${ }^{(3)}$
Resumo - A ferrugem-da-folha (Puccinia coronata f. sp. avenae) é a principal doença da cultura da aveia (Avena sativa L.), e o uso de cultivares resistentes é o método de controle mais importante. Este trabalho teve por objetivo determinar o controle genético da resistência à ferrugem-da-folha em aveia e identificar fontes de genes diferentes para resistência a esta doença. Foram utilizados três genótipos resistentes (UFRGS 15, UFRGS 881920 e UFRGS 86A1194-2), três genótipos suscetíveis (UFRGS 7, UFRGS 8 e UFRGS 14) e a geração segregante $\mathrm{F}_{3}$ proveniente dos cruzamentos entre estes genótipos. As plantas foram avaliadas individualmente quanto à presença ou ausência da ferrugem-da-folha, sendo os dados destas leituras utilizados numa análise genética em que a hipótese de um ou dois genes de resistência foi testada pelo qui-quadrado. Os resultados evidenciaram um gene dominante de resistência no genótipo UFRGS 881920 e dois genes complementares no genótipo UFRGS 15 quando estes foram cruzados com os suscetíveis. A análise genética feita não permitiu determinar se estes dois genótipos são ou não a mesma fonte genética de resistência.
\end{abstract}

Termos para indexação: Avena sativa, resistência a doenças, Puccinia coronata, doenças das plantas, controle genético.

\section{Genetics of crown rust resistance in oat}

\begin{abstract}
Crown rust (Puccinia coronata f. sp. avenae) is the main disease in the oat crop (Avena sativa L.) and the use of resistant cultivars is the most important control method. This study had as objective to determine the genetic control of resistance to crown rust in oat and to identify different gene sources for resistance to this disease. Three resistant genotypes (UFRGS 15, UFRGS 881920 and UFRGS 86A1194-2), three susceptible genotypes (UFRGS 7, UFRGS 8 and UFRGS 14) and the $\mathrm{F}_{3}$ progenies derived from crosses between these genotypes were used. The plants were evaluated individually with regard to the presence or absence of crown rust symptoms, and the data from these evaluations were used to perform a genetic analysis in which the hypothesis of one or two resistance genes were tested by the chi-square test. Results showed one dominant resistance gene in UFRGS 881920 and two complementary resistance genes in UFRGS 15 , when they were crossed with the susceptible genotypes. The genetic analysis performed did not allow to determine whether these two genotypes are or are not the same source of resistance.
\end{abstract}

Index terms: Avena sativa, disease resistances, Puccinia coronata, plant diseases, genetic control.

\section{Introdução}

A aveia (Avena sativa L.) é um cereal de estação fria, que se apresenta como uma excelente alternati-

(1) Aceito para publicação em 19 de outubro de 2000.

Extraído da Dissertação de Mestrado apresentada pelo primeiro autor à Universidade Federal do Rio Grande do Sul (UFRGS), Faculdade de Agronomia (FA), Porto Alegre, RS.

(2)UFRGS, FA, Dep. de Plantas de Lavoura, Caixa Postal 776, CEP 91501-970, Porto Alegre, RS. E-mail: rfcruz@cpovo.net

(3)UFRGS, FA, Dep. de Plantas de Lavoura. Bolsista do CNPq. E-mail: federizi@vortex.ufrgs.br,milach@vortex.ufrgs.br va no sistema de rotação com o trigo no inverno. O melhoramento genético da espécie possibilitou um aumento considerável do potencial de rendimento dos genótipos de $700 \mathrm{~kg} / \mathrm{ha}$ no início da década de 1960 para mais de $1.000 \mathrm{~kg}$ /ha na década de 1980 (Carvalho \& Federizzi, 1989). No entanto, a ocorrência de doenças ainda é um fator limitante à expressão deste potencial de rendimento. Dentre as doenças que atacam a cultura, a ferrugem-da-folha, causada pelo fungo Puccinia coronata f. sp. avenae, é a mais destrutiva e a de maior distribuição, pois ocorre em praticamente todos os locais de cultivo de aveia, mas 
de uma forma mais séria em condições de umidade elevada (Simons \& Murphy, 1961).

O uso de cultivares resistentes é o método de controle mais razoável, pois não implica aumento de custos, nem danos ao meio ambiente. Além disso, a resistência genética das cultivares tem proporcionado boa proteção à cultura, assegurando a expressão do potencial de rendimento dos genótipos.

A resistência genética, normalmente utilizada nos programas de melhoramento, tem sido a completa, condicionada por um ou poucos genes de resistência. Isto se deve principalmente à sua facilidade de seleção em populações segregantes, pois ela segrega em classes descontínuas. Contudo, este tipo de resistência tem permanecido eficiente por pouco tempo antes que o patógeno a supere (Ohm \& Shaner, 1992). Desta forma, a busca contínua por novas fontes de resistência à ferrugem-da-folha se faz necessária. Além do mais, o entendimento das bases genéticas da resistência dos genótipos existentes é bastante importante para que esse caráter possa ser manipulado eficientemente pelo melhorista.

Até o presente momento, inúmeros são os trabalhos publicados com relação ao estudo da herança da resistência à ferrugem-da-folha em aveia. Muitos deles relatam casos de herança monogênica da resistência (Harder et al., 1990; Chong \& Brown, 1994; Salmeron et al., 1994), assim como de genes complementares condicionando resistência à ferrugemda-folha da aveia (Gregory \& Wise, 1994). A existência de genes menores condicionando resistência raça-específica a esta doença em aveia foi observada por Sebesta (1983). A maioria destes estudos utiliza métodos artificiais de inoculação e raças específicas do patógeno para a avaliação da resistência, sendo normalmente conduzidos sob condições controladas, e as plantas, avaliadas ainda no estádio de plântula, mais ou menos 10 a 12 dias após o procedimento de inoculação do patógeno. Além disso, estes estudos foram conduzidos no exterior, e se referem a genótipos e ambientes muito distintos dos que são encontrados no Brasil. Assim, é importante que se estude a resistência genética à ferrugem-da-folha nos nossos ambientes e com os genótipos de aveia aqui utilizados, para que esta informação possa ser usada pelos programas de melhoramento no Brasil.
Este trabalho teve por objetivo estudar o controle genético da resistência à ferrugem-da-folha em genótipos brasileiros de aveia, e identificar diferentes fontes genéticas de resistência a esta doença.

\section{Material e Métodos}

O experimento foi conduzido na Estação Experimental Agronômica da Universidade Federal do Rio Grande do Sul, em Eldorado do Sul, RS, situada na região fisiográfica da Depressão Central. O solo pertencente à unidade de mapeamento São Jerônimo, classificado como Podzólico Vermelho-Escuro distrófico (IBGE, 1986), foi preparado pelo sistema convencional (aração e gradagens) e adubado com $300 \mathrm{~kg} / \mathrm{ha}$ da fórmula 5-20-20. Foram realizadas duas adubações de cobertura com $50 \mathrm{~kg} / \mathrm{ha}$ de uréia quando as plantas tinham três e seis folhas, respectivamente. $\mathrm{O}$ controle das plantas daninhas foi feito com capinas periódicas.

Em 1993, foram semeadas no campo, as gerações $F_{1} e$ $\mathrm{F}_{2}$ de nove cruzamentos. Em cada planta foi coletada a panícula principal e trilhada individualmente. No dia 24/6/94 foram semeados os genótipos genitores (Tabela 1) e a geração $F_{3}$ dos nove cruzamentos mencionados (Tabela 2), colocando-se 15 sementes por linha, de maneira a permitir a avaliação individual das plantas e mantendo-se a identificação da planta $\mathrm{F}_{2}$ que lhes deu origem. As linhas tinham $3 \mathrm{~m}$ de comprimento, com espaços de $0,30 \mathrm{~m}$. O número de linhas semeadas por cruzamento se encontra na Tabela 2. Os genótipos genitores foram semeados nas bordas de cada cruzamento, e foram semeadas duas linhas por genótipo. No dia 9/6/95 foram semeadas

Tabela 1. Genealogia e reação à ferrugem-da-folha de seis genótipos de aveia utilizados no estudo da herança da resistência a esta doença. UFRGS, 1995.

\begin{tabular}{|c|c|c|}
\hline Genótipo parental & Genealogia & $\begin{array}{l}\text { Reação à ferrugem-da- } \\
\text { folha à campo }{ }^{(1)}\end{array}$ \\
\hline UFRGS 7 & X 1205/FLA 1093 & S \\
\hline UFRGS 8 & OA 338/ X $2682-1$ & $\mathrm{~S}$ \\
\hline UFRGS 14 & $\begin{array}{l}80 \mathrm{SA} 65 / / \mathrm{COR}^{2} / \mathrm{CTZ}^{3} / \\
\text { Pendek/ ME } 1563\end{array}$ & S \\
\hline UFRGS 15 & $\begin{array}{l}\mathrm{COR}^{2} / \mathrm{CTZ}^{3} \text { / Pendek/ } \\
\mathrm{ME} 1563 / \mathrm{C} 16 \text { CRcpx/ } \\
\text { C 7512/ Srcpx/ } 74 \text { C } 8014\end{array}$ & $\mathrm{R}$ \\
\hline UFRGS 881920 & $\begin{array}{l}\text { Sel. CP16 Crcpx/ C 7512/ } \\
\text { Srcpx/ } 74 \text { C } 8014\end{array}$ & $\mathrm{R}$ \\
\hline UFRGS 86A1194-2 & M 921/ OT 224 & $R / S$ \\
\hline
\end{tabular}

(1)S: suscetível; R: resistente; R/S: resistência quebrada em 1994. 
28 cultivares diferenciais, cada uma delas constituindo uma linha com dez sementes cada, num total de 28 linhas (Tabela 3). O inóculo utilizado para a avaliação da resistência das plantas em 1994 e 1995 foi o que ocorre naturalmente no campo, já que a doença é endêmica e ocorre todos os anos nesta região.

Em 1994, as plantas foram avaliadas semanalmente quanto à presença ou ausência da ferrugem-da-folha, tendo sido consideradas resistentes as plantas com total ausência de sintomas da doença e suscetíveis aquelas em que foram constatados sintomas, não importando o grau de doença presente. As leituras tiveram início a partir da primeira ocorrência de pústulas no genótipo genitor mais suscetível, e continuaram até próximo do período de enchimento dos grãos. A partir dos dados coletados nestas leituras, foi contado o número de linhas resistentes, suscetíveis ou segregantes, e realizada uma análise genética de cada cruzamento, na qual a hipótese genética de um ou dois genes de resistência foi testada pelo teste do qui-quadrado (Steel \& Torrie, 1980). A hipótese de um gene foi testada na proporção três resistentes/segregantes : uma suscetível, esperada para o caso de a resistência ser condicionada por um gene dominante. A hipótese de dois genes foi testada na proporção nove resistentes/ segregantes : sete suscetíveis, esperada para o caso de a resistência ser devida a dois genes complementares. O teste das hipóteses foi feito pelo cálculo do qui-quadrado e comparação do valor calculado com o valor teórico de $5 \%$ de probabilidade e um grau de liberdade, uma vez que existem apenas duas classes (resistente/segregante e suscetível). A fórmula utilizada para o cálculo do qui-quadrado foi a seguinte:

$\chi^{2}=\sum$ (freqüência observada - freqüência esperada $)^{2} /$ freqüência esperada.

Em 1995, também foram realizadas leituras semanais nas cultivares diferenciais, planta a planta, quanto à presença ou ausência de doença, e contado o número de plan- tas infectadas, por cultivar, e os resultados expressos como porcentagem de plantas infectadas por diferencial.

\section{Resultados e Discussão}

Os resultados obtidos com relação ao número de linhas $\mathrm{F}_{3}$ resistentes/segregantes e suscetíveis de cada população encontram-se na Tabela 2 . A comparação dos valores observados em cada classe, com os valores esperados no caso de haver um ou dois genes complementares segregando nas populações, permitiu o cálculo dos valores de qui-quadrado correspondentes. A não-significância desses valores em relação ao valor teórico $\left(\chi^{2}{ }_{0,05(1)}=3,84\right)$ revela a adequação do modelo para explicar a segregação observada.

Assim, no caso dos cruzamentos envolvendo a linhagem resistente UFRGS 881920 e as cultivares suscetíveis UFRGS 7, UFRGS 8 e UFRGS 14, a hipótese de um gene com o alelo dominante conferindo resistência foi aceita pelo fato de o qui-quadrado calculado não ter sido significativo quando comparado com o valor tabelado (Tabela 2). O mesmo foi constatado no cruzamento entre UFRGS 881920 e a linhagem UFRGS 86A1194-2. Já no caso dos cruzamentos envolvendo o genótipo UFRGS 15 e os suscetíveis UFRGS 7, UFRGS 8 e UFRGS 14, a hipótese de um gene de resistência não foi aceita, e tampouco nos cruzamentos UFRGS 86A1194-2 x UFRGS 8 e UFRGS 881920 x UFRGS 15 (Tabela 2).

Os cruzamentos entre a cultivar resistente UFRGS 15 e as suscetíveis UFRGS 7 e UFRGS 14 evidenciaram a existência de dois genes em epistasia nestas populações, o que também foi constatado no

Tabela 2. Reação à ferrugem-da-folha em famílias $\mathrm{F}_{3}$ provenientes de cruzamentos entre genótipos de aveia resistentes e suscetíveis em Eldorado do Sul, em 1994. UFRGS, 1994.

\begin{tabular}{|c|c|c|c|c|c|}
\hline \multirow[t]{2}{*}{ População } & \multirow{2}{*}{$\begin{array}{l}\mathrm{N}^{\mathrm{o}} \text { de linhas } \\
\text { segregantes }\end{array}$} & \multicolumn{2}{|c|}{$\mathrm{N}^{\underline{0}}$ de famílias $\mathrm{F}_{3}$} & \multirow[t]{2}{*}{$\chi^{2}(3: 1)$} & \multirow[t]{2}{*}{$\chi^{2}(9: 7$} \\
\hline & & Resistentes/segregantes & Suscetíveis & & \\
\hline UFRGS 881920 x UFRGS 7 & 109 & 75 & 34 & 2,23 & $6,99 *$ \\
\hline UFRGS 881920 x UFRGS 8 & 67 & 51 & 16 & 0,04 & $10,74 *$ \\
\hline UFRGS 881920 x UFRGS 14 & 18 & 12 & 6 & 0,67 & 0,79 \\
\hline UFRGS 881920 x UFRGS 86A1194-2 & 30 & 22 & 8 & 0,53 & 3,56 \\
\hline UFRGS 881920 x UFRGS 15 & 112 & 65 & 47 & $17,20^{*}$ & 0,14 \\
\hline UFRGS 15 x UFRGS 7 & 163 & 86 & 77 & $41,48 *$ & 0,81 \\
\hline UFRGS 15 x UFRGS 8 & 198 & 130 & 68 & $8,64 *$ & $7,12 *$ \\
\hline UFRGS 15 x UFRGS 14 & 67 & 31 & 36 & $29,49 *$ & 2,72 \\
\hline UFRGS 86A1194- 2 x UFRGS 8 & 15 & 6 & 9 & $9,80^{*}$ & 1,62 \\
\hline UFRGS 881920 x suscetíveis & 194 & 138 & 56 & 1,55 & - \\
\hline UFRGS 15 x suscetíveis & 428 & 247 & 181 & - & 0,37 \\
\hline
\end{tabular}

${ }^{*}$ Significativo pelo teste de qui-quadrado a $5 \%$ de probabilidade $\left(\chi^{2}{ }_{0,05(1)}=3,84\right)$. 
cruzamento UFRGS 86A1194-2 x UFRGS 8. Na população proveniente do cruzamento de UFRGS 15 com UFRGS 8, no entanto, a hipótese de dois genes não foi aceita (Tabela 2).

O cruzamento entre os dois genótipos resistentes UFRGS 881920 e UFRGS 15 também revelou dois genes em epistasia para resistência à ferrugem-dafolha nesta população (Tabela 2).

Pelo fato de os cruzamentos entre o genótipo resistente UFRGS 881920 e os suscetíveis terem se comportado de forma semelhante, eles foram reunidos em um grupo único. O mesmo foi feito com os cruzamentos entre UFRGS 15 e os suscetíveis. Isto foi feito para avaliar de forma global os efeitos dos genótipos resistentes UFRGS 881920 e UFRGS 15 , independentemente da população na qual eles se encontravam. A segregação das populações provenientes dos cruzamentos entre a linhagem UFRGS 881920 e as cultivares suscetíveis indicou a existência de um gene segregando, sendo a resistência nestas populações condicionada pelo alelo dominante. Já as populações dos cruzamentos entre a cultivar resistente UFRGS 15 e as suscetíveis revelaram a existência de dois genes complementares de resistência à ferrugem-da-folha naquela cultivar (Tabela 2).

A herança da resistência à ferrugem-da-folha em aveia, conforme os dados acima, é do tipo monogênica e oligogênica nos genótipos UFRGS 881920 e UFRGS 15, respectivamente. Na literatura, outros trabalhos também relatam herança monogênica (Harder et al., 1990; Chong \& Brown, 1994; Salmeron et al., 1994) e alelos de genes complementares (Gregory \& Wise, 1994), como responsáveis pela resistência à ferrugem-da-folha em aveia. A resistência conferida por genes menores já foi observada em aveia por Sebesta (1983); no entanto, é mais comumente observada em cruzamentos envolvendo genótipos com resistência parcial e genótipos suscetíveis (Thomé, 1999).

No presente trabalho, também foi constatado que a resistência é dominante e a suscetibilidade, recessiva. Dick \& Johnson (1983), que estudaram a ferrugem-da-folha do trigo (Puccinia recondita), consideram a resistência, na maioria das vezes, dominante, ou, no mínimo, parcialmente dominante.

No cruzamento entre os dois genótipos resistentes UFRGS 881920 e UFRGS 15, foi constatado que estes diferem entre si por dois genes complementares de resistência. Este resultado, porém, não está de acordo com os de Dick \& Johnson (1983), segundo os quais se esperaria que os genótipos UFRGS 881920 e UFRGS 15 diferissem por três genes de resistência. Com base nos dados de segregação obtidos com relação ao caráter resistência, os genótipos das cultivares suscetíveis são supostamente do tipo aabb, do tipo $\mathrm{A}_{1} \mathrm{~A}_{1} \mathrm{bb}$ para o genótipo UFRGS 881920 e $\mathrm{A}_{2} \mathrm{~A}_{2} \mathrm{BB}$ para o genótipo UFRGS 15. No entanto, de acordo com esta hipótese, ao cruzar-se os dois genótipos resistentes não se obteria uma segregação de 9R:7S como foi encontrada, e sim 10R:6S. Esta última foi testada com relação aos dados, e não foi possível rejeitá-la $\left(\chi^{2}=0,96\right)$. Esta segregação pode ser explicada considerando-se duas pressuposições: a primeira é a de que há uma interação alélica de dominância de $\mathrm{A}_{2}$ sobre $A_{1}$, e a segunda é a de que há uma ação epistática de $B$ em relação a $A_{1}$ e $A_{2}$. Supõe-se que $B$ atue sobre o alelo $\mathrm{A}_{2}$ conferindo resistência, e, sobre o alelo $A_{1}$, como um inibidor da resistência. Desta forma, os genótipos $A_{2} B_{-}$e $A_{1} A_{1}$ bb seriam resistentes, e os genótipos $A_{2}$ b $b$ e $A_{1} A_{1} B$, suscetíveis. Conforme a hipótese proposta, os dois genótipos resistentes utilizados neste estudo seriam considerados a mesma fonte genética de resistência, pois possuiriam alelos diferentes de um mesmo gene. Entretanto, atualmente existem linhagens de aveia resistentes à ferrugem-da-folha no programa de melhoramento da UFRGS, e que foram selecionadas a partir do cruzamento entre estes dois genótipos, o que sugere que eles seriam diferentes fontes de resistência a esta doença. Com base nestes fatos, outra interpretação para os resultados é de que não foi possível elucidar totalmente as diferenças gênicas existentes entre os genótipos resistentes UFRGS 881920 e UFRGS 15 através dos cruzamentos utilizados neste estudo. Apenas que estes possuem, em relação aos suscetíveis, um gene dominante e dois genes complementares de resistência, respectivamente. Cabe destacar, ainda, que estes resultados dizem respeito a apenas um ano de avaliação, e que a segregação da resistência observada em algumas populações mostrou ser interessante à repetição do experimento. Em 1995, no entanto, ocorreu a quebra de resistência dos genótipos UFRGS 881920 e UFRGS 15, a qual impossibilitou a repetição da análise genética.

Apesar de a maioria dos estudos deste tipo ter sido realizada sob condições controladas com inoculação artificial do patógeno, neste trabalho optou-se por 
conduzir o experimento sob condições de campo, utilizando fonte de inóculo natural e realizando as avaliações da ocorrência da doença nas plantas durante todo o seu ciclo. Estes procedimentos permitem verificar que a resistência, cuja base genética se quer investigar, tem utilidade no programa de melhoramento, pois é detectada em condições naturais de campo e através do inóculo natural existente no ambiente, o qual constitui, em última instância, a pressão de seleção que o melhorista irá utilizar. A variabilidade do inóculo disponível no ambiente foi investigada pela avaliação do número de plantas infectadas por cultivar diferencial (Tabela 3). Cada uma das cultivares diferenciais identifica um gene de resistência (Pc 68, por exemplo), e sua infecção por ferrugem-da-folha é um indicador da existência, na população patogênica, do gene de virulência capaz de vencer o referido gene de resistência. Esta investigação foi realizada somente no ano seguinte ao do estudo genético, quando houve disponibilidade das referidas cultivares, porém ela tem utilidade no sentido de fornecer uma indicação da grande variabilidade existente quanto às raças de Puccinia coronata, na região de Eldorado do Sul. Na primeira leitura, quinze diferenciais - praticamente a metade delas - já apresentavam a doença. Dentre elas, destacam-se a Pc 40, Pc 46, Pc 54, Pc 56 e Pc 60 como as mais infectadas (mais de $50 \%$ das plantas atacadas). Na segunda leitura, apenas quatro diferenciais ainda estavam isentas da doença. São elas: a Pc 52, Pc 53, Pc 57 e Pc 62; todas as demais apresentavam ferrugem-da-folha, a maioria com mais de $50 \%$ das plantas infectadas. Na terceira e última leitura, todas as cultivares diferenciais testadas estavam infectadas por ferrugem-da-folha, e, na maioria delas, $100 \%$ das plantas apresentavam a doença (Tabela 3), o que indica uma alta freqüência das raças com os genes de virulência para os genes de resistência identificados pelas cultivares diferenciais.

De acordo com estes resultados, percebe-se a grande variabilidade com que o fungo Puccinia coronata f. sp. avenae se apresentou no ano de 1995 na região de Eldorado do Sul, pois foi capaz de atacar 28 diferentes genes de resistência. A alta variabilidade no inóculo natural de Puccinia coronata, constatada pelo estudo com as cultivares diferenciais, pode ser explicada pela ocorrência simultânea de várias raças
Tabela 3. Número de plantas de aveia avaliadas por cultivar diferencial no campo e número e porcentagem (entre parênteses) de plantas infectadas por ferrugem-da-folha, em cada leitura (11/8, 23/8 e 25/8), em 1995. UFRGS, 1995.

\begin{tabular}{lcllc}
\hline Diferencial & $\begin{array}{c}\text { Total de } \\
\text { plantas }\end{array}$ & $1^{\underline{a}}$ leitura & $2^{\underline{\underline{a}}}$ leitura & $3^{\text {a }}$ leitura \\
\hline Pc 14 & 8 & $2(25,0)$ & $7(87,5)$ & $8(100,0)$ \\
Pc 35 & 8 & 0 & $6(75,0)$ & $8(100,0)$ \\
Pc 36 & 7 & 0 & $7(100,0)$ & $7(100,0)$ \\
Pc 38 & 6 & 0 & $6(100,0)$ & $6(100,0)$ \\
Pc 39 & 6 & $1(16,8)$ & $6(100,0)$ & $6(100,0)$ \\
Pc 40 & 7 & $5(71,4)$ & $7(100,0)$ & $7(100,0)$ \\
Pc 45 & 9 & $2(22,2)$ & $9(100,0)$ & $9(100,0)$ \\
Pc 46 & 6 & $5(83,3)$ & $6(100,0)$ & $6(100,0)$ \\
Pc 48 & 7 & $2(28,6)$ & $4(57,1)$ & $7(100,0)$ \\
Pc 50 & 6 & 0 & $4(66,7)$ & $6(100,0)$ \\
Pc 51 & 9 & 0 & $2(22,2)$ & $2(22,2)$ \\
Pc 52 & 9 & 0 & 0 & $1(11,1)$ \\
Pc 53 & 10 & 0 & 0 & $4(40,0)$ \\
Pc 54 & 10 & $7(70,0)$ & $9(90,0)$ & $10(100,0)$ \\
Pc 55 & 5 & 0 & $5(100,0)$ & $5(100,0)$ \\
Pc 56 & 8 & $7(87,5)$ & $8(100,0)$ & $8(100,0)$ \\
Pc 57 & 8 & 0 & 0 & $7(87,5)$ \\
Pc 58 & 8 & 0 & $7(87,5)$ & $8(100,0)$ \\
Pc 59 & 6 & 0 & $4(66,7)$ & $6(100,0)$ \\
Pc 60 & 8 & $6(75,0)$ & $8(100,0)$ & $8(100,0)$ \\
Pc 61 & 6 & $2(33,3)$ & $6(100,0)$ & $6(100,0)$ \\
Pc 62 & 7 & 0 & 0 & $1(14,3)$ \\
Pc 63 & 9 & $1(11,1)$ & $5(55,6)$ & $8(88,9)$ \\
Pc 64 & 9 & $2(22,2)$ & $5(55,6)$ & $7(77,8)$ \\
Pc 67 & 8 & $2(25,0)$ & $8(100,0)$ & $8(100,0)$ \\
Pc 68 & 9 & $1(11,1)$ & $1(11,1)$ & $1(11,1)$ \\
Pc 70 & 8 & 0 & $4(50,0)$ & $6(75,0)$ \\
Pc 71 & 7 & $2(28,6)$ & $6(85,7)$ & $6(85,7)$ \\
\hline & & & &
\end{tabular}

simples ou pela ocorrência de poucas raças complexas do patógeno, ou seja, com vários genes de virulência. Assim, a resistência genética detectada no presente estudo deve ser efetiva contra um grande número de raças simples ou complexas.

Nas condições ambientais deste estudo, foi possível detectar no genótipo resistente UFRGS 881920 um gene com o alelo dominante conferindo resistência à ferrugem-da-folha e dois genes complementares, cujos alelos dominantes condicionaram resistência no genótipo UFRGS 15, quando foram cruzados com os suscetíveis UFRGS 7, UFRGS 8 e UFRGS 14.

\section{Conclusões}

1. O caráter resistência à ferrugem-da-folha em aveia é de herança simples e oligogênica, e é condicionado por um alelo dominante no genótipo 
UFRGS 881920 e dois alelos dominantes de genes complementares no genótipo UFRGS 15.

2. Não é possível detectar a existência de fontes genéticas diferentes para resistência à ferrugem-dafolha em aveia.

3. O patógeno Puccinia coronata f. sp. avenae apresenta uma grande variabilidade nas condições ambientais de Eldorado do Sul, e o inóculo natural existente no campo apresenta muitos genes de virulência.

\section{Referências}

CARVALHO, F. I. F.; FEDERIZZI, L. C. Evolução da cultura da aveia no sul do Brasil. Trigo e Soja, Porto Alegre, n. 102, p. 16-19, 1989

CHONG, J.; BROWN, P. D. Genetics of resistance to Puccinia coronata in two Avena accessions from the National Research Germplasm Institute, Bari, Italy. Oat Newsletter, Minneapolis, v. 42, p. 27, 1994.

DICK, P. L.; JOHNSON, R. Temperature sensitivity of genes for resistance in wheat to Puccinia recondita. Canadian Journal of Plant Pathology, Ottawa, v. 5, n. 4, p. 229-234, 1983.

GREGORY, J. W.; WISE, R. P. Linkage of genes conferring specific resistance to oat crown rust in diploid Avena. Genome, Ottawa, v. 37, n. 1, p. 92-96, 1994.

HARDER, D. E.; CHONG, J.; BROWN, P. D.; MARTENS, J. W. Inheritance of resistance to Puccinia coronata avenae and $P$. graminis avenae in an accession of Avena sterilis from Spain. Genome, Ottawa, v. 33, n. 2, p. 198-202, 1990.

IBGE (Rio de Janeiro, RJ). Folha SH.22 Porto Alegre e parte das folhas SH.21 Uruguaiana e SI.22 Lagoa Mirim: geologia, geomorfologia, pedologia, vegetação, uso potencial da terra. Rio de Janeiro, 1986. 796 p. (Levantamento de recursos naturais, 33). Continuação da série editada pelo extinto Projeto RADAMBRASIL.

OHM, H. W.; SHANER, G. Breeding oat for resistance to diseases. In: MARSHALL, H. G.; SORRELLS, M. E. (Ed.). Oat science and technology. Madison: American Society of Agronomy/Crop Science Society of America, 1992. p. 657-698. (Agronomy Monograph, 33).

SALMERON, J. J.; HARDER, D. E.; CHONG, J. Inheritance of stem and crown rust resistance in three Mexican oat lines. Oat Newsletter, Minneapolis, v. 42, p. 36, 1994.

SEBESTA, J. Race-specific expression of oat crown rust resistance conditioned by major and minor genes. Euphytica, Dordrecht, v. 32, n. 3, p. 857-861, 1983.

SIMONS, M. D.; MURPHY, H. C. Oat diseases. In: COFFMAN, F. A. (Ed.). Oats and oat improvement. Madison : American Society of Agronomy, 1961. p. 330390.

STEEL, R. G. D.; TORRIE, J. L. Principles and procedures of statistics. 2. ed. New York : McGraw-Hill, 1980. 418 p.

THOMÉ, G. C. H. Genética e análise molecular da resistência parcial à ferrugem-da-folha em aveia. Porto Alegre : UFRGS, 1999. 129 p. Tese de Doutorado. 